\title{
AS TIRINHAS NAS AULAS DE LEITURA EM LÍNGUA INGLESA: UMA PROPOSTA DIDÁTICO-PEDAGÓGICA PARA INICIANTES
}

\author{
Daniela Gomes de Araújo Nóbrega*
}

\begin{abstract}
Resumo: Este artigo discute a pedagogia de leitura multimodal nas aulas de língua inglesa (LI) para alunos iniciantes. Fruto de um minicurso para a III Jornada PIBID/UEPB Letras-Inglês/2015, este artigo sugere como os professores podem trabalhar com o gênero textual 'Tirinha'. Para tanto, como teoria usei Bazerman (2006) sobre a noção de gênero; sobre as características da linguagem não verbal, utilizei Ekman e Friesen (1969) e Nóbrega (2011); sobre o gênero textual tirinha, mencionei Barbosa (2014), Vergueiro e Ramos (2015); e sobre leitura interativa e multimodal, usei Kleiman (2012) e Rojo (2012). Como proposta didático-pedagógica, recomendo atividades que associam a leitura multimodal (imagética) com o texto escrito, dando ênfase às habilidades orais/ escrita dos alunos.
\end{abstract}

Palavras-chaves: Ensino de Leitura. Língua Inglesa. Imagens. Iniciantes.

Abstract: This article discusses the pedagogy of multimodal reading in English language (EL) classes for beginners. As a result of a short course for the III Jornada PIBID/UEPB Letters-English /2015, this article suggests how teachers can work with the genre 'Strips'. To this end, as a theory I used Bazerman (2006) on the notion of gender; about the characteristics of non-verbal language, Ekman and Friesen (1969) and Nóbrega (2011) were used; on the genre 'Strips', it was considered the work of Barbosa (2014), Vergueiro and Ramos (2015); and about interactive and multi-modal reading, I used Kleiman (2012) and Rojo (2012). As a didactic and pedagogical proposal, I recommend activities that combine multimodal reading (imagery) with the written text, giving emphasis on the learners' oral or written skills.

Keywords: Teaching of Reading. English language. Images. Beginners.

\section{Considerações iniciais}

Se considerarmos que a linguagem não verbal consiste em toda forma não verbal de se comunicar, então o que fazemos enquanto falamos com alguém é, por si só, um ato comunicativo. Os gestos, o movimento da cabeça, um olhar discreto ou surpreso que usamos cotidianamente, por exemplo, podem suscitar inúmeros significados e, impreterivelmente, nos ajudam a compreender o que e como alguém está querendo nos comunicar algo.

Em sala de aula também usamos a linguagem não verbal de formas variadas e distintas, e também em momentos diferentes. Quando estamos tirando dúvidas dos nossos alunos, quando nossos alunos nos perguntam algo e quando todos interagem ora em momentos de descontração ora em momentos de questionamentos e/ou de explicação de algo, os gestos e o nosso corpo estão falando constantemente e, algumas vezes, contradizem o que falamos. Tal postura não verbal pode ser explorada em aulas de leitura em língua estrangeira (Inglês), sobretudo quando trabalhamos com o gênero textual - Tirinhas - com nossos alunos (cf. BARBOSA, 2014; VERGUEIRO; RAMOS, 2015).

Inserido nos estudos da Pragmática (LEVINSON, 1983; MEY, 2001), este artigo discorre sobre o uso da linguagem não verbal (imagética ou quadrinhista) nas tirinhas e de como nós, professores de língua estrangeira, no nosso caso de língua inglesa, podemos utilizálas para auxiliar os alunos nas aulas de leitura. De acordo com Levinson (1983) e Mey (2001), todo tipo de linguagem só pode ser discutida à luz de um determinado contexto. Contexto este que nos proporciona verificar todo tipo de pista, linguística e/ou extralinguística, para buscarmos compreender o uso da linguagem durante qualquer evento comunicativo.

\footnotetext{
* Professora Doutora do Departamento de Letras e Artes - Letras Língua Inglesa, Centro de Educação, da Universidade Estadual da Paraíba. Endereço eletrônico: danielanobrega5@gmail.com
} 
No que tange analisar a linguagem não verbal/imagética/quadrinhista nas tirinhas, podemos inferir que tal linguagem só pode ser estudada se verificarmos como os personagens usam as palavras e expressões que eles escolheram para fazer uso, o que estes personagens fazem enquanto falam e a repercussão de suas falas e ações nos outros personagens. Estudar o gênero textual - tirinhas - pela perspectiva não verbal nos permite explorar outros níveis de leitura e, consequentemente, proporcionar aos alunos ir além das palavras, da leitura puramente verbal. Ler as imagens, as ações e outras formas semióticas deste gênero rico em significados multimodais pode contribuir para melhor entendermos a mensagem das tirinhas, objeto alvo de discussão neste artigo.

Fruto de um minicurso para a III Jornada PIBID/UEPB Letras-Inglês/2015, este trabalho apresenta e discute a possibilidade de se trabalhar com o gênero textual 'Tirinha' em aulas de leitura em Língua Inglesa (LI) com turmas de iniciantes. Assim sendo, este artigo dividi-se em 5 (cinco) partes. Na primeira parte, discorremos sobre o conceito mais amplo de gênero textual com base em Bazerman (2006). Na segunda parte, falamos sobre o significado da linguagem não verbal (EKMAN; FRIESEN, 1969) pontuando o aspecto imagético e multimodal que o gênero Tirinha apresenta. Na terceira, apresentamos as características sobre o gênero textual Tirinha. Na quarta, discutimos sobre o modelo interativo e multimodal de leitura trazendo à tona concepções com base em Kleiman (2012) e Rojo (2012). E na quinta parte, apresentamos uma proposta pedagógica que explora o aspecto não verbal (imagético) das Tirinhas nas aulas de leitura em LI.

\section{Falando sobre gênero textual}

Dentre as várias definições de gênero textual que temos conhecimento, a que usamos neste artigo é a de “(...) padrões comunicativos com os quais as outras pessoas estão familiarizadas, e que elas podem reconhecer mais facilmente o que estamos dizendo e o que pretendemos realizar" (BAZERMAN, 2006, p. 29). Estamos falando aqui de formatos de um evento comunicativo específico que, segundo este autor, se relaciona com situações com as quais as pessoas se familiarizam, i.e. compartilham este conhecimento. Por exemplo, quando falamos de festa infantil, e que tipo de cartão de aniversário precisamos organizar para convidar os amigos, já temos em mente o formato e o tipo de informação que precisamos usar (nome e idade do aniversariante, data e local da festa, e endereço).

Definimos também os gêneros textuais, também chamados de discursivos, por "características textuais" que nos sinalizam o que eles representam. Estas características textuais nos permitem visualizar a tipologia do texto e o propósito que o gênero se propõe (cf. BAZERMAN, 2006). Cartas, e mail, blog, contrato, receita de bolo, HQs, charges, horóscopo e resenhas, por exemplo, são alguns gêneros textuais que apresentam em sua formatação características diferentes por apresentarem objetivos comunicativos distintos. Para ilustrarmos, enquanto as charges apresentam de forma breve mensagens de natureza política com pitadas de humor, as histórias em quadrinhos são mais extensas e podem também apresentar conteúdos de humor.

Além das características textuais, os "gêneros tipificam muitas coisas além da forma textual. São parte do modo como os seres humanos dão forma às atividades sociais". (BAZERMAN, 2006, p. 31) Aqui estamos falando sobre situações sociais e o padrão de acontecimentos destas situações. Situações do nosso cotidiano como casamento noturno, festa de aniversário infantil, missa dominical, por exemplo, seguem um determinado padrão de acontecimentos do qual os participantes envolvidos comumente conhecem. Quando conhecemos estes padrões de acontecimento, podemos dizer que os participantes compartilharam deste saber. Quando, pelo contrário, os participantes desconhecem sobre o 
que naturalmente acontece em situações do cotidiano, dizemos que os participantes desconhecem o que deve acontecer num determinado gênero.

Portanto, (re)conhecer um tipo de gênero textual, como é o caso das Tirinhas, objeto de discussão deste trabalho, nos possibilita conhecer sobre o propósito comunicativo do gênero e das características textuais que ele apresenta. Com estas informações já conhecidas antes de uma leitura, certamente, os alunos que estão começando a aprender inglês como língua estrangeira poderão melhor entender a mensagem que perpassa naquele gênero. A seguir, apresento as características da linguagem não verbal que estão presentes no gênero textual, tirinhas.

\section{Linguagem não verbal e as tirinhas}

Para o antropólogo Norte-Americano Erving Goffman, “(...) muitas das propriedades da fala terão de ser vistas como alternativas a atos extralinguísticos, ou equivalentes funcionais deles" (2002, p. 19). Segundo Goffman, estes gestos funcionais são fundamentais para entendermos o que uma pessoa fala, por exemplo. São estes gestos que "propiciam estados de fala, gestos que policiam esses estados de fala" (p. 19) e, portanto, fazem parte da comunicação verbal entre os interlocutores em qualquer evento social. Estes gestos funcionais, do qual Goffman tanto fala, podem ser vistos na linguagem não verbal que, impreterivelmente, estão presentes em toda forma de comunicação.

Definir a linguagem não verbal, dentro da perspectiva de Goffman (2002), pode estar relacionado com toda forma não verbal, que vai desde as gravuras, imagens e fotografias até os gestos e expressões faciais que usamos quando nos comunicamos. Este tipo de linguagem, contudo, também pode ser compreendida por meio de várias categorias. Dentro dos estudos da linguagem não verbal podemos citar (1) a proxêmica, (2) a cinésica, (3) a tacsênica, (4) o estudo do toque e do olhar, e (5) a paralinguagem.

A Proxêmica é o estudo dentro da linguagem não verbal que lida com a distância entre os interlocutores e o grau de relacionamento que determinadas distâncias podem determinar. Por exemplo, podemos verificar que numa situação formal vista entre o médico e um paciente numa clínica, a distância entre os dois não é tão próxima como a de dois amigos que estão almoçando. Numa clínica médica, por exemplo, o médico normalmente atende o paciente apertando a sua mão de forma educada, pedindo-o para sentar e depois começa a verificar o seu estado de saúde. Tal comportamento revela, nesta situação, a não aproximação afetiva e apenas um contato profissional. A proxêmica, portanto, também pode pesquisar o grau de afetividade entre as pessoas através da distância que estes participantes adotam nas suas relações (EKMAN; FRIESEN, 1969; NÓBREGA, 2011).

Por sua vez, a cinésica estuda os movimentos corporais relativos à fala. Neste tipo de estudo, podemos analisar aspectos tais como os gestos, o movimento do corpo, as expressões faciais, o contato dos olhos, o sorriso. Todas estas expressões podem revelar emoções importantes que tanto podem complementar, monitorar ou contradizer a fala (referências). Ao complementar a fala, por exemplo, o sorriso pode nos revelar alegria e satisfação. Isto pode ser constatado numa pesquisa em sala de aula. Descrevendo e analisando o sorriso dos alunos em trabalhos em grupos, Nóbrega (2011) verificou que este sorriso pode sinalizar satisfação dos alunos em compartilhar uma tarefa e, consequentemente, a produção oral em língua inglesa pode ser mais vista.

Embora não tão vistos e pesquisados, a tacsênica e o comportamento do olhar (eye contact) também merecem destaque. O elemento não verbal, 'olhar', tende a ser investigado para analisarmos como os interlocutores sinalizam (i) interesse ou (ii) ausência de interesse na 
relação, aproximação ou na falta de aproximação e, consequente, afetividade (cf. EKMAN; FRIESEN, 1969; NÓBREGA, 2011).

A tacsênica, entretanto, estuda o toque nas relações sociais e a consequente implicação no grau de aproximação entre as pessoas numa dada situação social (cf. EKMAN; FRIESEN, 1969; NÓBREGA, 2011). Tal aspecto pode ser visto se analisarmos as relações entre professor e alunos nos países orientais como China e Japão. Entre professor e alunos nestes dois países, por exemplo, normalmente existe uma relação um pouco distante e pouco uso do toque denotando educação e respeito para com o outro. Este tipo de relação já é visto diferente entre professor e alunos nos países ocidentais como Brasil, por exemplo. O toque entre as pessoas nas relações sociais no Brasil, por sua vez, traz uma conotação de aproximação e afetividade. O estudo da tacsênica, portanto, traz à tona questões sobre afetividade nas relações, questão esta que também merece ainda mais pesquisas no contexto de sala de aula.

Sobre a paralinguagem, podemos dizer que esta categoria estuda os sons vocais. Este estudo inclui o ritmo, tom de voz, entonação e estresse, isto é, são os aspectos supra segmentais da fala. De acordo com Gumperz (1982), estes aspectos paralinguisticos que estão presentes na fala podem indicar certas posturas e posição social dos interlocutores, revelando, assim, suas condutas diante de outros que os estão vendo. São, portanto, estes aspectos da linguagem não verbal que sinalizam quando alguém está sendo irônico quando fala algo que não condiz com a verdade; quando alguém está mentindo ou dizendo a verdade ou até quando alguém está traindo. $\mathrm{O}$ tom de voz, por exemplo, pode indicar determinadas posturas que podem aproximar ou afastar as pessoas. A pessoa tida como autoritária ou mandona tende a apresentar uma postura rígida, com um tom de voz severo e rouco. Ou seja, o tom de voz pode sinalizar as intenções e sentimentos dos interlocutores no ato de fala (cf. EKMAN e FRIESEN, 1969; NÓBREGA, 2011).

Portanto, ao lermos as tirinhas, todos estes aspectos da linguagem não verbal que foram citados até aqui podem e devem ser explorados em aulas de leitura em língua inglesa. Ler é entender o que e como os personagens estão falando, como eles estão interagindo entre si e, as mensagens que estão querendo passar para o leitor, implicam em estarmos atentos nas expressões faciais, no movimento corporal, no olhar, e nas várias formas não verbais mostradas pelos personagens nas tirinhas. A seguir, apresentamos, de forma breve, as características deste gênero textual, as tirinhas.

\section{As tirinhas}

O gênero textual, Tirinhas, tem sido denominado e discutido a partir de um gênero textual maior, ou hipergênero: as Histórias em Quadrinhos (HQs). Portanto, falar sobre as Tirinhas nos remete também sobre as HQs.

Inicialmente criada nos Estados Unidos, a tirinha ou tira de jornal surgiu devido à falta de espaço nos jornais para a publicação dos passatempos. Por ser de natureza híbrida e curta, isto é, por conter aspectos textuais orais e escritos e ser apresentado de forma sequienciada, este gênero caiu no gosto dos leitores de jornal. Além disto, as possuem outra característica bem peculiar que atrai seus leitores: humor nas estórias (cf. BARBOSA, 2014; VERGUEIRO; RAMOS, 2015).

$O$ fato de unir o texto escrito informal com as imagens faz com que este gênero não somente atraia o público infanto-juvenil, inicialmente público-alvo deste tipo de gênero, mas também tem atraído o grupo adulto por apresentar características da realidade por um viés mais humorado. Como Vergueiro e Ramos (2015) explicam, os gêneros híbridos como as Tirinhas, Charges e Histórias em Quadrinhos (HQs) "são dispositivos visuais gráficos que 
veiculam e discutem aspectos da realidade social, apresentando-a de forma crítica e com muito humor" (p.11).

Assim como as HQs, as Tirinhas possuem uma linguagem informal, diálogos curtos e recursos icônicos - verbais próprios (balões, onomatopéias, metáforas visuais, figuras cinéticas) que possibilitam o leitor a unir a imagem ao texto escrito oralizado pelos personagens, facilitando, desta forma, a compreensão da leitura. Além destas peculiaridades, o conteúdo temático das Tirinhas é bem diversificado e geralmente estão associados às questões da realidade. Temas tais como ecologia, reciclagem, proteção ao planeta Terra são abordados nos gibis e/ou Tirinhas da Turma da Mônica (cf. VARGAS; MAGALHÃES, 2011).

O uso das Tirinhas em aulas de leitura, de forma geral, tem sido bastante explorado, tanto que o ENEM (Exame Nacional do Ensino Médio) no Brasil (cf. BARBOSA, 2014; VERGUEIRO, 2014; VERGUEIRO; RAMOS, 2015), tem também usado nas provas no intuito do aluno-leitor explorar o recurso não verbal/imagético como estratégia de leitura. Conforme Vergueiro et. al argumentam, as tirinhas “(...) se apresentam como uma sequência de quadros que trazem uma mensagem ao leitor, normalmente uma narrativa, seja ela ficcional ou real" (2014, p. 32).

Para este trabalho, o uso das tirinhas nas aulas de leitura em LI possui dois objetivos. O primeiro uso está relacionado para atrair o interesse na leitura em LI por ser um gênero multimodal - apresenta uma variedade de linguagens a ser usada pelo leitor. Isto é, concordando com o que Rojo (2012) explica sobre multiletramentos, o gênero tirinha é híbrido e multimodal por apresentar "textos compostos de muitas linguagens e que exigem capacidades e práticas de compreensão e produção de cada uma delas (multiletramentos) para fazer significar" (p.19). Na leitura de tirinhas, o aluno/leitor precisa associar a leitura das imagens, cores, movimentos corporais dos personagens com o texto escrito (diálogo dos personagens) em sequência, i.e. de quadro em quadro. Esta leitura sequencial e de modos (linguagens) diferentes permite ao aluno/leitor perceber que um tipo de linguagem pode auxiliar na compreensão da estória como um todo; uma vez que um tipo de linguagem pode ajudar na compreensão de outro tipo de linguagem.

O segundo objetivo em usar este gênero nas aulas de leitura está em associar as habilidades da língua em vários momentos da aula. Em uma aula, por exemplo, o professor pode associar a leitura silenciosa com a escrita, i.e. a leitura pode servir como a habilidade inicial e insumo para motivar os alunos a escrever outras estórias. Em outro momento, o professor pode usar a leitura em voz alta para trabalhar a pronúncia e a entonação dos diálogos, propiciando também a dramatização com os alunos; uma alternativa eficiente para desenvolver a produção oral dos alunos. Por ser um gênero de várias semioses, isto é, de linguagens diferentes em um único espaço (cf. ROJO, 2012), a leitura passa a ser vista como um processo interativo em que exige do leitor uma capacidade em interagir dinamicamente com o texto, assunto este, tema da próxima seção.

\section{Concepção interativa e multimodal de leitura}

Dentre os modelos e/ou concepções de leitura que a teoria nos apresenta (ascendente, descendente e interativo), o modelo interativo ou sócio- interativo de leitura é o que mais se enquadra para se trabalhar com as Tirinhas nas aulas de Leitura em LI.

Nesta concepção de leitura, as operações cognitivas usadas geralmente por um leitor proficiente são aquelas que privilegiam o conhecimento prévio, conhecimento linguístico, conhecimento enciclopédico, conhecimento textual e conhecimento léxico-estrutural (cf. KLEIMAN, 2012). O conhecimento prévio diz respeito ao conhecimento de mundo e das 
experiências já vividas pelo leitor; o conhecimento linguístico envolve tanto o lexical e o estrutural, isto é, são conhecimentos sobre o significado das palavras e da morfo-sintaxe da língua; e o conhecimento textual se refere ao conhecimento tanto dos tipos de texto (narrativo, descritivo, dissertativo e juntivo) como dos gêneros textuais que circulam em várias situações comunicativas do cotidiano. Todas as operações necessárias para se ativar todos os conhecimentos, aqui já citados, são usadas na leitura de Tirinhas. Quando, por sua vez, um destes conhecimentos não é de conhecimento do leitor, o professor precisa fazer uso do recurso não verbal/imagético para auxiliar na leitura da Tirinha.

$\mathrm{Na}$ leitura multimodal, o processo de ler e compreender o que se lê não é muito diferente da concepção interativa apresentada anteriormente. Uma prática multimodal ou multissemiótica de leitura envolve uma leitura de diversidade de linguagens situadas num único espaço. Por exemplo, a leitura na internet é uma leitura multimodal porque inclui a leitura do texto escrito, de imagens, de sons, cores, às vezes movimentos, áudio e links (cf. ROJO, 2012). Para este tipo de leitura são exigidas novas práticas de leitura chamada de multiletramentos, pois são necessários novos conhecimentos para ler e compreender o que se lê. Ao lermos as tirinhas, precisamos ter consciência desta diversidade de linguagens presente neste gênero. Imagens, cores, onomatopéias, diálogos, expressões faciais dos personagens são alguns exemplos de linguagens encontradas nas tirinhas. Saber como usá-las para beneficiar a compreensão, requer uma prática multimodal, isto é, demanda uma consciência multissemiótica do leitor que é a de associar as várias formas de linguagem ao texto escrito.

Por sua vez, na concepção interativa de leitura, todo o conhecimento (de mundo, de língua, de imagem) é usado para processar a leitura. No desconhecimento de um, outro tipo de conhecimento pode ser acionado. Por exemplo, ao ler uma Tirinha, o aluno-leitor por desconhecer certas palavras pode usar a imagem e a situação da estória para ajudá-lo a inferir o significado de uma determinada palavra. Para ilustrar, podemos verificar o uso destes conhecimentos com a Tirinha da Turma da Mônica abaixo:

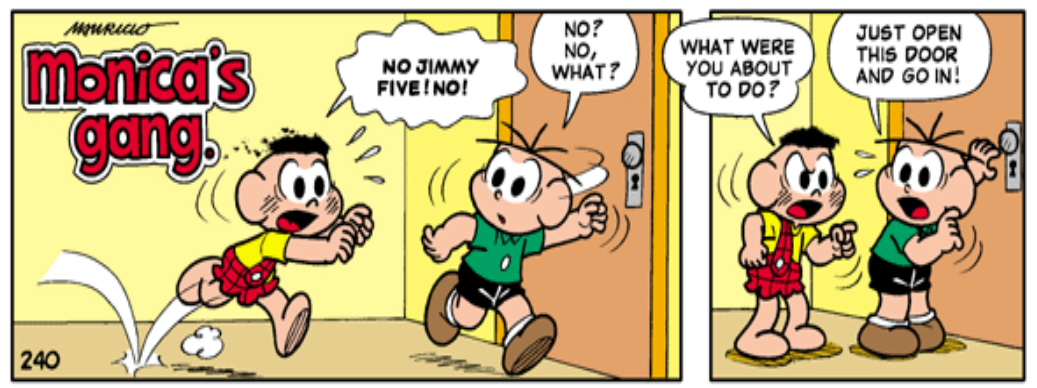

Figura 1: Tirinha Smudge and Jimmy five

Fonte: http://17minutosdeingles.blogspot.com.br/2012/10/normal-0-21-false-false-false-pt-br-x.html

Nesta Tirinha, o aluno-leitor, sobretudo o iniciante de língua inglesa, pode desconhecer o verbo frasal 'go in' na estória. Em contrapartida, este mesmo aluno pode conhecer o tipo de situação que os personagens estão vivenciando. Estes conhecimentos, o de mundo e de situação, podem auxiliar para o leitor tentar compreender o que significa 'go in'. Neste caso, foram acionados o conhecimento prévio do aluno-leitor - ao analisar a situação, e o conhecimento das ações dos personagens - ao analisar o que os personagens fazem na estória. Estes dois tipos de conhecimentos podem ser usados como ferramentas auxiliares no processamento da leitura por ajudar na inferência de significado de palavras desconhecidas.

A concepção de leitura aqui processada foi, primeiro, a interativa porque dois tipos de conhecimentos foram acionados para auxiliar o aluno-leitor na compreensão da estória/tirinha: o de mundo e o linguístico. A segunda concepção foi a multimodal pelo fato de o aluno/leitor ter de associar as ações (movimento corporal e expressões faciais) dos 
personagens Cebolinha e Cascão com o diálogo usado por eles. Este conjunto de conhecimentos - escrito, de gestos, expressões faciais e de mundo - está impreterivelmente situado numa prática multimodal e interativa, prática esta cada vez mais exigida na sociedade contemporânea do século XXI.

\section{Tirinhas em aulas de leitura em língua inglesa: uma proposta de leitura}

Na leitura de Tirinhas, a leitura não verbal (também chamada multimodal para a leitura de Tirinhas) é constantemente requerida, fazendo com que o leitor assuma uma leitura sequencial, de quadro em quadro, e considerando também todos os aspectos envolvidos nos quadros (cores, movimento corporal dos personagens, onomatopeias, olhares, expressões faciais, etc.). Esta leitura imagética ou, nas palavras de Kress (1998), as estruturas visuais, i.e. imagens, realizam significados assim como a leitura de estruturas linguísticas também fazem.

Usadas como um recurso pedagógico, as imagens das Tirinhas podem ser usadas de formas variadas numa aula de leitura em LI que enfatiza o desenvolvimento das estratégias de leitura. Na parte de pré-leitura, por exemplo, podemos explorar as imagens como forma de chamar a atenção dos alunos-leitores à situação em que a estória ocorre. Neste momento, podemos recorrer às ações dos personagens, o que eles estão fazendo, a forma como eles estão dispostos, e em como eles interagem. Na Tirinha, cada sequência evidencia um significado que leva a sequência seguinte a formar um significado global. Na tirinha abaixo, mostraremos como a fase da pré-leitura pode ser feita.

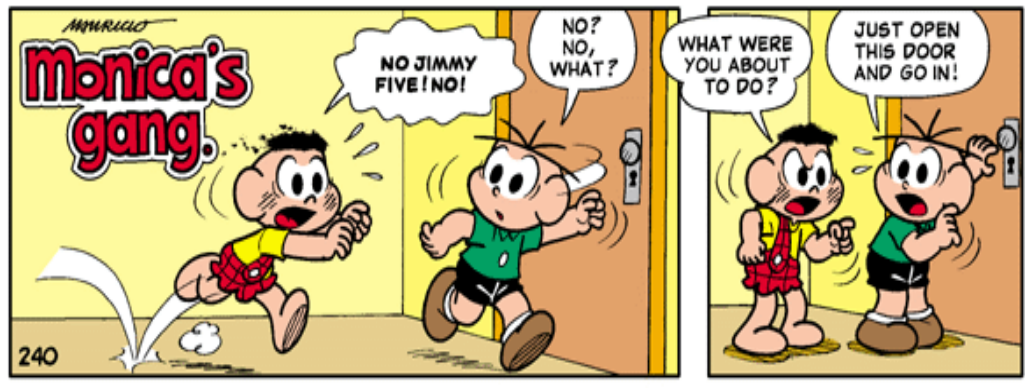

Figura 2: Tirinha Smudge and Jimmy five

Fonte: http://17minutosdeingles.blogspot.com.br/2012/10/normal-0-21-false-false-false-pt-br-x.html

Nesta tira, o personagem Cascão (Smudge) está chamando a atenção de Cebolinha (Jimmy Five) correndo em direção dele. Tal ação - correr em direção a ele - está também vinculada à expressão facial de Cascão que sugere que ele (Cebolinha) não deve fazer algo, expresso pela sua fala - No Jimmy Five! No! Nesta primeira sequência, tanto a expressão facial de Cascão como a de Cebolinha - expressão de surpresa - parecem sinalizar que o assunto trazido por Cascão não é dos melhores; há algo estranho que pode (ou não) acontecer.

Ainda nesta mesma sequência, podemos unir a imagem, neste caso a expressão facial de Cascão e Cebolinha, à fala dos dois personagens. Daí surge a conexão entre imagem e palavras/frases/expressões, ou seja, a imagem com o texto escrito. Típico de gêneros híbridos, o texto oral acrescenta ou complementa informações ao texto visual dando maior visibilidade à construção global da sequência narrativa (BARBOSA, 2014; VERGUEIRO et. al., 2014; VERGUEIRO; RAMOS, 2015). Neste processo de compreender o que está se passando na Tirinha, cabe ao leitor interpretar estes dois veículos de informação - visual e escrito.

Como alternativa de atividade de leitura, a habilidade oral também pode ser explorada com leituras orais. Considerando que as falas nas tirinhas são exemplos típicos de textos orais informais, i.e. falas do cotidiano infantil, podemos utilizá-las para explorar o uso 
de gírias e/ou outras expressões típicas de fala em detrimento da linguagem escrita formal, mais encontradas em gêneros textuais escritos como artigos científicos, resenhas, monografias, etc. Ainda neste aspecto em se trabalhar com a habilidade da fala, nas Tirinhas podemos explorar as características das falas dos personagens em conjunto com as estruturas gramaticais usadas por eles. Frases curtas, verbos no imperativo, verbos frasais tais como o encontrado na Tirinha acima - No, what? Just open this door and go in - podem ser ensinadas a fim dos alunos-leitores possam depois criar suas próprias estórias como atividade de sala ou de casa.

Outra forma de se trabalhar com as Tirinhas em sala de aula, sobretudo com crianças, pode envolver a habilidade da escrita com desenhos. Neste momento, estamos trabalhando com a fase da pós-leitura, fase esta em que nós, professores, avaliamos o que os alunosleitores aprenderam na leitura da Tirinha. Pedir aos alunos para desenharem sobre o que eles entenderam ou elaborararem uma estória com desenhos pode ser uma maneira de incentivar os alunos para criarem outras estórias a partir do que eles previamente leram. Esta concepção de leitura pode desencadear nos alunos-leitores a (re)criarem estórias outras, fazendo-os ser conscientes que toda estória tem conexão com outras estórias.

Esta noção de intertextualidade (cf. KLEIMAN, 2012) presente não somente em qualquer texto (oral ou escrito), mas também nos textos em que (re)criamos, pode desenvolver nos alunos-leitores a consciência de que todo tipo de conhecimento - textual, linguístico, de mundo, imagético e multimodal - interage em prol de um propósito maior: a de leitura de mundo que, como já afirmava Paulo Freire, antecede a leitura de palavras. Esta concepção de leitura, levada para a sala de aula, pode desenvolver nos alunos-leitores de LI a concepção crítica de leitura fazendo-os desenvolver a leitura multisemiótica como o pontapé inicial para a leitura do texto escrito.

\section{Considerações finais}

De acordo com o que foi apresentado e discutido neste artigo, pode-se inferir que trazer à tona para a aula de leitura em LI com iniciantes uma visão multimodal (imagética ou quadrinhista) de leitura, possibilita os alunos a perceberem este tipo de linguagem com outros olhos. Ler e compreender uma língua estrangeira, no nosso caso a LI, não está apenas associada a ler e entender o vocabulário e a estrutura linguística contidos no texto escrito. Assim como fazemos, de forma geralmente automática, na leitura em língua materna, podemos orientar os nossos alunos a lerem as imagens ou fotos ou qualquer outro tipo de linguagem não verbal quando estiverem acompanhando os textos escritos. Fazendo isto, estamos motivando nossos alunos a exercitarem leituras de modos diferentes, leituras estas que nos conscientiza sobre a leitura que fazemos, de forma involuntária, no nosso cotidiano. Afinal de contas, antes de lermos o que está escrito no papel, somos educados desde cedo a ler o mundo ao nosso redor, cheio de cores, formas, sons e movimentos. Este modo de ver e ler o mundo é que nossos alunos de LI já são habituados a ler cotidianamente. Partindo disto, este artigo apresenta este exemplo multimodal de proposta didático-pedagógica.

\section{Referências}

BARBOSA, A. Como usar as histórias em quadrinhos na sala de aula. In: BARBOSA, A.; RAMOS, P.; VILELA, T.; RAMA, A.; VERGUEIRO, W. (Orgs.). 4. ed., 2. reimpressão. São Paulo: Contexto, 2014. 
BAZERMAN, C. Gêneros Textuais, tipificação e interação. In: BAZERMAN, C.; DIONÍSIO, A. P.; HOFFNAGEL, J. C. (Orgs.) 2. ed., São Paulo: Cortez, 2006.

EKMAN, P.; FRIESEN, W. The repertoire of nonverbal behavior: categories, origins, usage and coding. Semiótica, 1, 1969. Disponível em: www.paulekamn.com/publications/jounalarticles-book-chapters/ Acessado em: 05/01/10.

GOFFMAN, E. A Situação Negligenciada. In: RIBEIRO, B. T.; GARCEZ, P. M. (Orgs.). Sociolinguística Interacional. 2. ed., São Paulo: Loyola, 2002, p. 13-20.

KLEIMAN, A. Oficina da Leitura: teoria e prática. 14. ed., Campinas, São Paulo: Pontes Editores, 2012.

KRESS, G.; LEEEUWEN, T. V. Reading Images: the grammar of visual design. Routledge: London, 1998.

LEVINSON, S. C. Pragmatics. Cambridge: Cambridge University Press, 1983.

MEY, J. L. Pragmatics: an introduction. 2. ed. Blackwell: U.S.A, 2001.

NÓBREGA, D. G. A de. A Fala do professor e o sorriso dos alunos na sala de aula em Língua Inglesa. In: BERGSLEITHNER, J. M.; WEISSHEINER, J.; MOTA, M. B. (Orgs.). Produção Oral em LE: múltiplas perspectivas. Coleção: Novas Perspectivas em Linguística Aplicada, v. 19, Campinas: Pontes Editores. 2011, p. 261-290.

RAMOS, P.; VERGUEIRO. Quadrinhos na educação: da rejeição à prática. 1. ed., $2^{\mathrm{a}}$ reimpressão, São Paulo: Contexto, 2015.

ROJO, R. Pedagogia dos Multiletramentos. In: ROJO, R.; MOURA, E. (Orgs.), Multiletramentos na escola. São Paulo: Parábola Editorial, 2012, p. 11- 31.

VERGUEIRO, W.; RAMA, A.; VILELA, T.; RAMOS, P.; BARBOSA, A. Como usar as histórias em quadrinhos na sala de aula. 4. ed. , 2. reimpressão, São Paulo: Contexto, 2014.

Recebido em: abril de 2016.

Aprovado em: agosto de 2016. 